\title{
Recent advances in the development of tissue transglutaminase (TG2) inhibitors
}

\author{
E. Badarau $\cdot$ R. J. Collighan $\cdot$ M. Griffin
}

Received: 30 July 2011/ Accepted: 29 November 2011

(C) Springer-Verlag 2011

\begin{abstract}
Tissue transglutaminase (TG2) is a $\mathrm{Ca}^{2+}$ dependent enzyme and probably the most ubiquitously expressed member of the mammalian transglutaminase family. TG2 plays a number of important roles in a variety of biological processes. Via its transamidating function, it is responsible for the cross-linking of proteins by forming isopeptide bonds between glutamine and lysine residues. Intracellularly, $\mathrm{Ca}^{2+}$ activation of the enzyme is normally tightly regulated by the binding of GTP. However, upregulated levels of TG2 are associated with many disease states like celiac sprue, certain types of cancer, fibrosis, cystic fibrosis, multiple sclerosis, Alzheimer's, Huntington's and Parkinson's disease. Selective inhibitors for TG2 both cell penetrating and non-cell penetrating would therefore serve as novel therapeutic tools for the treatment of these disease states. Moreover, they would provide useful tools to fully elucidate the cellular mechanisms TG2 is involved in and help comprehend how the enzyme is regulated at the cellular level. The current paper is intended to give an update on the recently discovered classes of TG2 inhibitors along with their structure-activity relationships. The biological properties of these derivatives, in terms of both activity and selectivity, will also be reported in order to translate their potential for future therapeutic developments.
\end{abstract}

Keywords Tissue transglutaminase - TG2 - Inhibitors · Structure-activity relationships (SAR)

E. Badarau · R. J. Collighan · M. Griffin ( $\square)$

School of Life and Health Sciences, Aston University,

Aston Triangle, Birmingham B4 7ET, UK

e-mail: m.griffin@aston.ac.uk

\begin{tabular}{ll}
\multicolumn{2}{l}{ Abbreviations } \\
TGase & Transglutaminase \\
SAR & Structure-activity relationship \\
HYD & Hydrophobic \\
HBA & Hydrogen bond acceptor \\
GTP & Guanosine triphosphate \\
GDH & Glutamate dehydrogenase \\
5-BP & 5-Biotinamidopentylamine \\
$t$ Boc & tert-Butyloxycarbonyl \\
Cbz & Benzyloxycarbonyl \\
Fmoc & Fluorenylmethyloxycarbonyl \\
Ac & Acetyl
\end{tabular}

\section{Introduction}

Transglutaminases are enzymes that perform post-translational modifications of proteins via an aminoacyltransferase reaction involving nucleophilic substitution at the gamma amide of a peptide-bound glutamine, with elimination of ammonia. The nucleophile may be the $\varepsilon$-amino group of a peptide lysine, another primary amine or water. In this way, $\varepsilon(\gamma$-glutamyl)lysine cross-links may be formed between proteins, peptide glutamines may be derivatised by primary amines, or peptide glutamines may be deamidated to glutamate. The protein cross-linking activity of transglutaminases is one of the most understood, resulting in the stabilisation of protein structures both against biological and mechanical degradation. Transglutaminases have been described in microorganisms, plants, invertebrates, amphibians, fish, birds and mammals. In mammals, transglutaminases are $\mathrm{Ca}^{2+}$ activated and important for the stabilisation of structures such as skin, hair and blood clots. The most ubiquitous mammalian transglutaminase is tissue 
transglutaminase (TG2) and has been the subject of much research due to its association with a variety of disease states such as metastatic cancer, celiac disease, fibrosis and neurodegenerative disorders. The role of TG2 in the pathology of these diseases is still unclear, although transamidating activity has been shown to be important. The development of selective inhibitors that regulate TG2transamidating activity therefore have the potential to act as novel therapeutic solutions. However, given the multifunctional roles of the eight active members of the mammalian transglutaminase family (Chen and Mehta 1999; Griffin et al. 2002), selectivity therefore concerns not only being selective for inhibition of transglutaminases but also being selective for inhibition of one or more of the transglutaminase members. Moreover, selectivity for particular transglutaminase members would help elucidate their specific biological roles.

To date, inhibitors of transamidation activity have been generally classified in two distinct subclasses depending on the inactivating mechanism of the enzyme: reversible (competitive or non-competitive) and irreversible inhibition. The competitive inhibitors are typically derivatives that include in their structure a medium to long saturated aliphatic chain bearing a terminal primary amine. This type of substrates were summarized previously (Lorand and Conrad 1984) and include among others putrescine and cadaverine-derived inhibitors, like 5-biotinamidopentylamine (5-BP), monodansyl cadaverine, fluorescein cadaverine (Fig. 1a-d). These type of compounds block cross-linking by acting as competitive primary amine substrates and become incorporated into the $\gamma$-glutamyl residue(s) of the peptide or protein substrate. Although useful for in vitro studies, in vivo they have limited application since the aminated protein could feasibly elicit an autoimmune response. Moreover, they have the potential to act as competitive substrates for all the transglutaminase enzymes.

Many of the non-competitive reversible inhibitors reported up-to-date allosterically inactivate the enzyme by competing for the TG2 cofactor (GTP, GDP, etc.) binding site. Thieno[2,3- $d]$ pyrimidin-4-one acylhydrizides identified by Case and co-workers (Duval et al. 2005; Case and Stein 2007) belong to this class of inhibitors (Fig. 1e). However, when designing such compounds, it must be taken into consideration that other members of the TG family, e.g. TG3 and TG5 also bind guanine nucleotides (Ahvazi et al. 2004; Candi et al. 2004).

Tissue transglutaminase irreversible inhibitors are probably the most widely studied type of TG 2 inhibitors in the last 15 years. The majority target the active site CYS residue of the mammalian TGs, and incorporate in their structure an essential electrophilic warhead able to covalently react with the highly nucleophilic sulphur atom from the catalytic site CYS residue, therefore totally inactivating the enzyme. Importantly, using the information gathered from the active sites of crystal structures of TG3, Factor XIII and TG2 and from information gathered from the preferred peptide amino acid sequences acting as TGase substrates (Hitomi et al. 2009; Sugimura et al. 2011) they allow greater specificity to be achieved against the target TG.

The classical approach to design irreversible inhibitors was a "simplification" approach, which means designing derivatives structurally related to their preferred natural $\gamma$-glutamyl-containing substrates, but with a simplified chemical structure, more easy to modulate for the desired pharmacological profile. Several series of peptidic
Fig. 1 Chemical structures of some reversible TG2 inhibitors

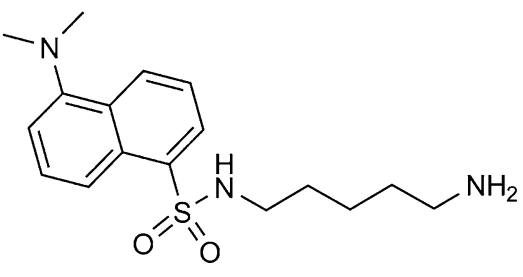

(a) monodansyl cadaverine

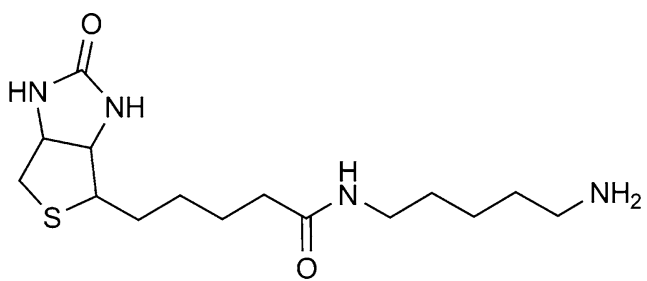

(b) biotinamidopentylamine<smiles>NCCCCCNC(=S)Nc1ccc(C2=C3C=CC=CC3Oc3ccccc32)c(C(=O)O)c1</smiles>

(d) fluorescein cadaverine<smiles>NNC(=O)CSc1nc2scc(-c3ccccc3)c2c(=O)n1-c1ccccc1</smiles>

(e) thieno[2,3- $d]$ pyrimidin-4-one acylhydrazide 
Fig. 2 Examples of previously reported peptidic irreversible inhibitors<smiles>O=C(NC(Cc1ccc(O)cc1)C(=O)NCC1CC(Br)=NO1)OCc1ccccc1</smiles>

KCC009<smiles>COC(=O)[C@H](CC(C)C)NC(=O)C1CCCN1C(=O)[C@@H](NC(=O)[C@H](CCC(=O)C=[N+]=[N-])NC(=O)OCc1ccccc1)C(C)(C)C</smiles><smiles>[R]CCC[C@H](NC(=O)OCc1ccccc1)C(=O)NCC(=O)O</smiles>

$\mathrm{R}=$<smiles>C=CC(N)=O</smiles><smiles>O=C(N[C@@H](CCCCN1C(=O)C=CC1=O)C(=O)OCc1ccccc1)OCc1ccccc1</smiles>

inhibitors emerged following this concept, the chemical structure of the warhead being generally used to differentiate among them (Fig. 2): 3-halo-4,5-dihydroisoxazoles (Choi et al. 2005; Watts et al. 2006; Castelhano et al. 1988), epoxides (de Macedo et al. 2002; Marrano et al. 2001b), $\alpha, \beta$-unsaturated amides (de Macedo et al. 2002; Marrano et al. 2001b; Pardin et al. 2006), chloroacetamides (Pardin et al. 2006), thiadiazoles (Marrano et al. 2001a), maleimides (Halim et al. 2007; Pardin et al. 2006), sulfonium methyl ketones (Pliura et al. 1992).

One of the most promising inhibitors described to date belongs to the dihydroisoxazole family (KCC009, Fig. 2). With a good pharmacokinetic profile and a good bioavailability in mice, this compound was tested in a human colon cancer cell line where it was shown to increase chemo-sensitivity of the tumour (Choi et al. 2005) in the range 1-100 $\mu \mathrm{M}$. However, Verhaar et al. (2011) showed that KCC009 was unable to affect TG2 activity up to a concentration of $100 \mu \mathrm{M}$ in their SH-SY5Y cell lines. Contrarily, the 6-diazo-5-oxo-noerleucine (DON) derivative Z006 which penetrates into cells (Fig. 2) induced a near complete inhibition of cellular TG2 at a concentration of $10 \mu \mathrm{M}$ (20-fold higher than in in vitro assays). Moreover, KCC009 does not affect the TG2-regulated formation of Mallory Bodies inside hepatocytes (Strnad et al. 2006) suggesting it may have limited intracellular activity.

\section{Recently discovered classes of tranglutaminase 2 inhibitors}

The main intention of this article is to review the recently reported TG2 inhibitors along with their structure-activity relationships (SAR) and their known specificity and applications to date. For a comprehensive view on this topic, the reader is also suggested to consult the previously published reviews (Siegel and Khosla 2007; Wodzinska 2005).

Cinnamoyl derivatives as TG2 inhibitors

Starting from a comparative study between Cbz-Gln-Gly versus Boc-Gln-Gly-binding modes via molecular modeling (Chica et al. 2004) but also from the privileged interaction of the benzyloxycarbonyl $(\mathrm{Cbz})$ moiety from several TG2 peptidic inhibitors with the enzyme's binding site, the group of Keillor further investigated the importance of rigidity of this carbamate moiety (Pardin et al. 2008a). Their efforts led to the identification of trans-cinnamoyl derivatives as competitive reversible TG2 inhibitors (Fig. 3), with $\mathrm{IC}_{50}$ values for guinea pig liver TGase ranging from $18->200 \mu \mathrm{M}$. The most potent inhibitors were divided in two subclasses, depending on the nature of the heteroaromatic substituent (HET) moiety: benzotriazolyl or pyridinyl.

Initial SAR on the aromatic cinnamoyl scaffold showed that substituents in the para position (preferably with a $\mathrm{sp}_{2}$ hybridized oxygen, e.g. $-\mathrm{NO}_{2}$, BocHN-, FmocNH-, AcNH-, -COOMe) positively influenced the affinity, while other substituents ( $\mathrm{Me}-, \mathrm{MeO}-, \mathrm{Cl}-$ ) had an unfavourable effect on binding. The observed $\mathrm{IC}_{50}$ values were as low as $18 \mu \mathrm{M}$ in the case of $p$-BocHN substituent and a 3-pyridyl as the HET moiety. The biological evaluation of their flexible analogues (the alkene is reduced or replaced by methylene-ether) showed a loss of activity. Moreover, the introduction of a supplementary conjugated alkene was 
Fig. 3 General structure of cinnamoyl derivatives and their SAR tendencies (Pardin et al. 2008a) substituent $(\mathrm{R})$ containing a $\mathrm{sp}_{2}$ hybridized $\mathrm{O}$ enhances activity

Influence of the substitution position: $4>3>>2$ heteroaromatic substituents (HET) favorable: benzotriazole, imidazole, pyridines

modification not tolerated

(eg. extended conjugation, increased flexibility in saturated series)

Fig. 4 General structure of triazole transglutaminase inhibitors and their SAR trends (Pardin et al. 2008b)

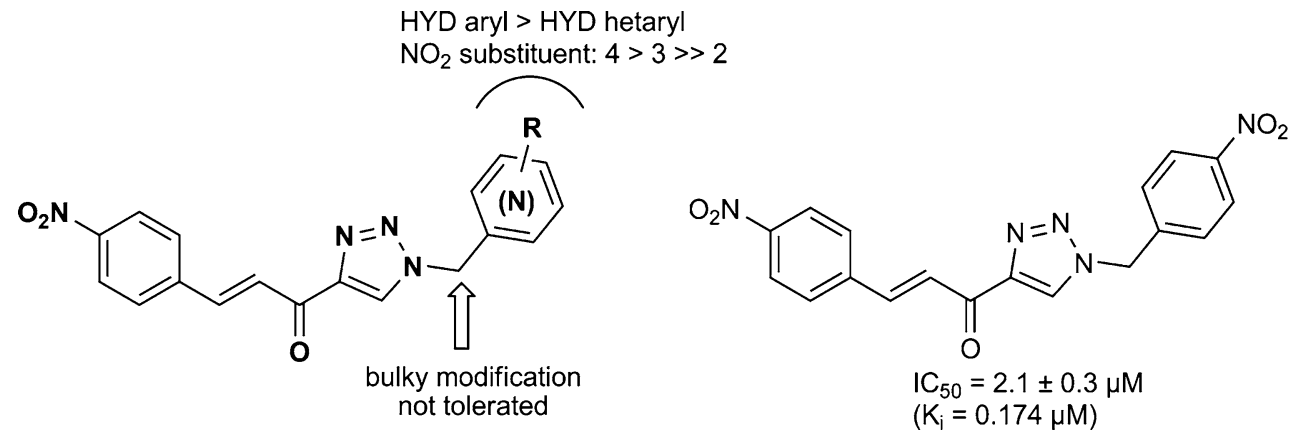

detrimental to the TG2 affinity, compared to their shorter analogues. Screening of several amines (aliphatic or aromatic) as the HET moiety had a negative impact on the affinity, as well as $\mathrm{Bz}$ and $t \mathrm{BuO}$ ethers. The overall conducted modulations showed that an aromatic moiety possessing hydrogen bond acceptors (HBA) is mandatory for a good affinity in this series of compounds (Fig. 3). This group of inhibitors seem to have a good selectivity profile since no inhibition of FXIII or caspase-3 was detected up to $200 \mu \mathrm{M}$ as showed by direct continuous colorimetric assays (Leblanc et al. 2001).

Further development of this cinnamoyl series was reported subsequently by the same group (Pardin et al. 2008b). Starting from the hypothesis that an aromatic heterocycle containing HBA atoms was essential for a good affinity (see above), various substituted triazoles were synthesized and evaluated (Fig. 4).

The conducted modulations showed that an alkyl substituent on the triazole ring generally induced a onefold increase of affinity. For example, compared to the parent non-substituted triazole $\left(\mathrm{IC}_{50}=45 \pm 0.5 \mu \mathrm{M}\right)$, introducing a benzyl substituent resulted in an $\mathrm{IC}_{50}$ decrease to $4.3 \pm 0.3 \mu \mathrm{M}$. The interaction between the triazole substituent and the binding site is most probably hydrophobic, since a cyclohexylmethyl substituent retains the affinity (although slightly lower) compared to its aromatic analogue $\left(\mathrm{IC}_{50}=11.0 \pm 1.5 \mu \mathrm{M}\right.$ vs. $\left.\mathrm{IC}_{50}=4.3 \pm 0.3 \mu \mathrm{M}\right)$. The newly discovered inhibitor (Fig. 4) did not protect or potentiate cell death induced by oxygen-glucose deprivation when used on cells expressing wild type TG2. Up to its toxicity limit $(20 \mu \mathrm{M})$ it did inhibit ionomycin-induced increases of transamidation activity for cells expressing the wt TG2 and in cells transfected with the TG2-R580A mutant (Colak et al. 2011).

Although the reversible cinnamoyl-based inhibitors were in silico modelled to accommodate the acyl donor substrate-binding site, further empirical proof was necessary to sustain this hypothesis. A new derivative (Fig. 5) incorporating a diazirine warhead was designed and enabled photolabelling of TG2 residues in its proximity, in the active-binding pocket (Pardin et al. 2009). Due to the ability of alkyl diazirines to generate diazo and carbene derivatives by photoactivation (Brunner 1993; Ziebell et al. 2004), this photolabile inhibitor was proved by mass spectrometry to covalently react with the Cys 230 residue. Native polyacrylamide gel electrophoresis showed that the enzyme-bound inhibitor adopts an open-form conformation [analogous to the reported crystal structure resolved in 2007 (Pinkas et al. 2007)], despite contradictory molecular modelling studies by the same authors, which suggested a more solvent exposed Cys230 residue in the closed conformation.

Inhibitors identified by the screening of libraries

Several potent hits for TGase were identified during highthroughput screening assays (Lai et al. 2008) of two libraries of pharmacologically active compounds: LOPAC (1,280 cpds) and Preswick (880 cpds). The most interesting derivatives validated via a first soluble-phase 
<smiles>CC1(CCC(=O)Nc2ccc(/C=C/C(=O)c3cccnc3)cc2)NN1</smiles>

Fig. 5 Structure of the cinnamoyl photolabile inhibitor (Pardin et al. 2009)

fluorescent dansylated lysine (KxD) incorporation assay and a subsequent colorimetric biotinylated pentylamine (BP) incorporation assay (which eliminate fluorescence interference) were subjected to a Triton X-100 test, known to eliminate false-positives induced by non-specific smallmolecule aggregates (McGovern et al. 2003). Figure 6 summarizes the most interesting hits found following this approach.

All the compounds inhibited TG2 irreversibly in the presence of $\mathrm{Ca}^{2+}$. However, when reducing agent DTT was included in the transglutaminase reaction their activity was significantly reduced, which the authors suggested was due to the inhibitors promoting the formation of disulfide bonds that inactivated the enzyme. Surprisingly, in the absence of $\mathrm{Ca}^{2+}$ several ligands were found to reversibly bind to the enzyme but Tyrphostin-47 was the only inhibitor, which competed with the GTP for its binding to TG2. Concerning the selectivity profile, beside their original protein targets listed in the screening database, the compounds were tested against blood coagulation factor FXIII, by using the same biotin pentylamine incorporation assay. They were found to be equipotent for FXII as for TG2, except for the vitamin K3, which had a sixfold decrease of affinity for FXIII.

A more complete biological profile for these hits, but also for other several classes of transglutaminase inhibitors, was reported by Macdonald and co-workers (Schaertl et al.

Fig. 6 Hits discovered via a HTS approach (Lai et al. 2008)<smiles>O=C1Nc2ccc(I)cc2/C1=C/c1cc(Br)c(O)c(Br)c1</smiles>

GW 5074 $\mathrm{IC}_{50}=50 \pm 5 \mu \mathrm{M}$<smiles>O=C1C(SCCO)=C(SCCO)C(=O)c2ccccc21</smiles>

NSC 95397 $\mathrm{IC}_{50}=2.5 \pm 0.6 \mu \mathrm{M}$
2010). During their efforts for developing a profiling platform for characterizing TG2 inhibitors, the authors investigated the TGase activity over a panel of transglutaminase isoforms (TG1, TG2, TG3, TG6 and FXIII), but also conducted a number cell activity studies and toxicity assays. However, it should be mentioned that, in the case of cellular assays, no data indicating the membrane permeability were reported. The biological results for the hits previously discovered by screening (Lai et al. 2008) are presented in Table 1.

Beside the biological characterization of previously reported inhibitors, the authors also revealed the SAR for new quinazolinone derivatives. Developed from the acylhydrazides published by Cuny and co-workers (Duval et al. 2005), their efforts led to the discovery of a highly potent $(20 \mathrm{nM})$ and selective inhibitor for TG1, TG3 and FXIII. However, no specific structures and additional cellular data were disclosed. The overall SAR trends in this series are presented below (Fig. 7).

\section{$\beta$-Aminoethyl ketones as TG2 inhibitors}

Even if the $\mathrm{IC}_{50}$ of the previously reported hit ZM 39923 $\left[\mathrm{IC}_{50}=0.01 \pm 0.01 \mu \mathrm{M}\right.$ (Lai et al. 2008); Fig. 6] was found to be only $4 \mu \mathrm{M}$ in their activity assays, this derivative was the starting point of an extensive SAR study published by Mikoshiba and co-workers (Ozaki et al. 2010). The authors stated that the original $\beta$-aminoethyl ketone framework proved essential for the TGase binding, contrary to their $\alpha$ - or $\mu$-aminoalkyl ketone analogues. Various aromatic ketones in both carbocyclic and heterocyclic series were investigated: heteroaromatic ketones appeared to be more favoured compared to the aromatic substituents, thiophene and furan showing the best results. The most potent ligand from this series as well as the SAR<smiles>CC(C)N(CCC(=O)c1ccc2ccccc2c1)Cc1ccccc1</smiles>

ZM 39923 , $\mathrm{IC}_{50}=0.01 \pm 0.01 \mu \mathrm{M}$<smiles>CC1(C)CCC2=C(O1)c1ccccc1C(=O)C2=O</smiles>

beta-lapachone, $I_{50}=20 \pm 2 \mu \mathrm{M}$<smiles>CC1=CC(=O)c2ccccc2C1=O</smiles>

Menadione $\mathrm{IC}_{50}=5.5 \pm 2 \mu \mathrm{M}$<smiles>N#C/C(=C/c1ccc(O)c(O)c1)C(N)=S</smiles>

Tyrphostin 47, $\mathrm{IC}_{50}=4 \pm 2 \mu \mathrm{M}$<smiles>CN(N=O)c1ccc(O)c(O)c1</smiles>

Me-3,4-dephostatin, $\mathrm{IC}_{50}=36 \pm 10 \mu \mathrm{M}$ 
Table $1 \mathrm{IC}_{50}(\mu \mathrm{M})$ values obtained for the screening hits (see Fig. 6 for molecular structures), modified from (Schaertl et al. 2010)
Fig. 7 SAR trends of acylhydrazides (Duval et al. 2005; Schaertl et al. 2010)
Fig. 8 SAR trends and the most potent derivative in $\beta$-aminoethyl ketone series (Ozaki et al. 2010)

\begin{tabular}{llllllllr}
\hline Compound & hTG2 & mTG2 & Cellular TG2 & hTG1 & hTG3 & FXIIIa & Caspase-3 & Tox \\
\hline GW 5074 & 4.6 & 10.6 & 1 & 5.7 & 2.7 & 3.9 & 70 & 25 \\
ZM 39923 & 2.8 & 1 & $>50$ & 2.9 & $>80$ & 1.7 & 47 & 50 \\
Tyrphostin 47 & 45 & 59 & $>50$ & 16 & 6.4 & 11.4 & $>50$ & 0 \\
NSC 95397 & 1.3 & 2.1 & $>50$ & 0.93 & 0.5 & 0.41 & $>50$ & 30 \\
$\beta$-Lapachone & 0.75 & 1.1 & $>50$ & 0.6 & 0.38 & 0.37 & 0.19 & 3 \\
Menadione & 2.6 & 6.6 & $>50$ & 2.9 & 1.8 & 2.1 & 6 & 20 \\
\hline
\end{tabular}

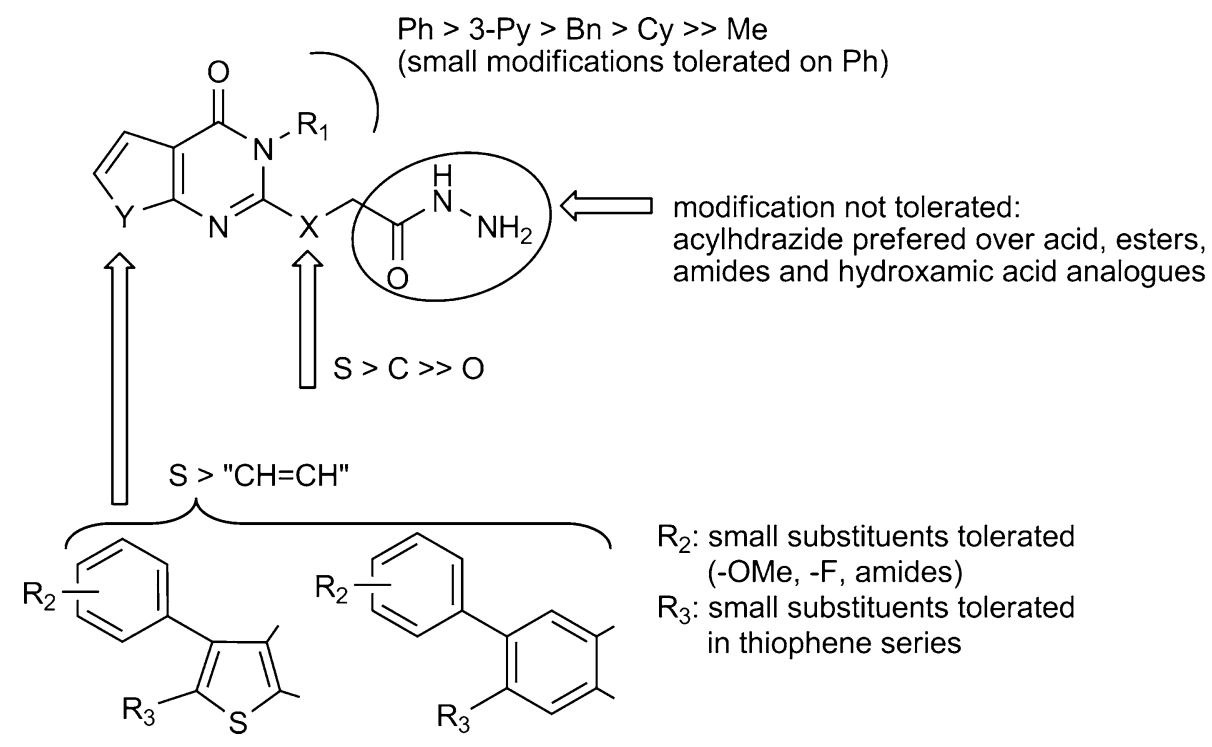<smiles>[X]c1ccc(C=C)c(C=C)c1</smiles>

Methyl tolerated; $\mathrm{Br}>\mathrm{Cl}>2,5 \mathrm{diCl}>>\mathrm{H}$

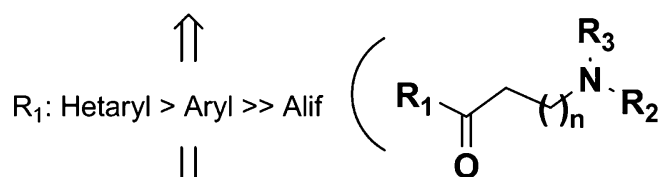

n: $1>>0$ or 2

$\mathrm{R}_{2}: t \mathrm{Bu}=\mathrm{iPr}>\mathrm{Et}>\mathrm{Me}>>\mathrm{H}$

$\mathrm{R}_{3}: \mathrm{Bn}>1$-hydroxyethyl<smiles>CC(C)(C)N(CCC(=O)c1ccc(Br)s1)Cc1ccccc1</smiles>

$\mathrm{IC}_{50}=0.081 \mu \mathrm{M}$

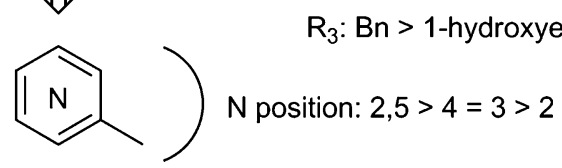

trends from the investigated compounds are presented below (Fig. 8).

In relation to the well-known affinity of disulfide compounds for transglutaminases (Connellan and Folk 1969; Chung and Folk 1970), of which recent examples include cystamines (Okauchi et al. 2009), the group of Mikoshiba has developed a series of disulfide dimers starting from the same $\beta$-aminoethyl ketone building block (Ozaki et al. 2011). This new series of derivatives, when tested for their effects on TGase activity (Ozaki et al. 2010), showed affinities in the $0.12-19 \mu \mathrm{M}$ range. Again, the thienyl ketone substituent conserved the best interaction with the 
binding site of TG among all the tested aromatic substituents (Fig. 9).

\section{Oxindole-based TG2 inhibitors}

The screening of the Navigator's iResearch library for TG2 inhibitors by Griffin and co-workers, led to the identification of various 2-oxindoles derivatives with TGase inhibitory activity (Klock et al. 2011). Besides some dimers with $\mu \mathrm{M}$ affinity for TG2, the screening also identified a more interesting compound, prone to further pharmacomodulations: 2-acylidenoxindole (Fig. 10). It is worth mentioning that the same scaffold was discovered earlier (Lai et al. 2008) during their screening assays (compound GW 5074, Fig. 4). Modulation of substituents $R_{1}, R_{2}$ and $R_{3}$ (Fig. 10) showed that the oxindole's aromatic moiety is the most

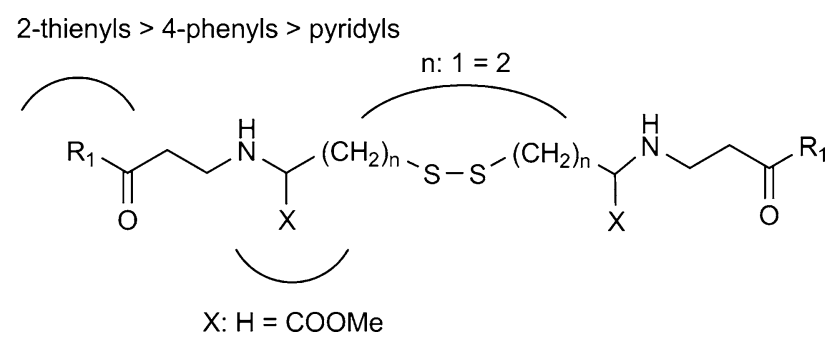

Fig. 9 SAR tendencies for the dithio- $\beta$-aminoethylketones (Ozaki et al. 2011)

Fig. 10 Initial hit from screening, SAR trends and the most potent compound in oxindole series (Klock et al. 2011)

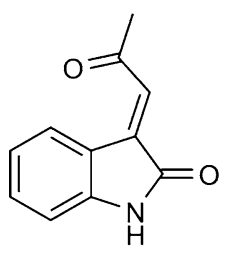

$$
\mathrm{IC}_{50}(\mathrm{a})=11 \mu \mathrm{M}
$$$$
\mathrm{IC}_{50}(\mathrm{~b})=19 \mu \mathrm{M}
$$

sensitive region of the molecule for the interaction with the TG2-binding site, $\mathrm{a}-\mathrm{Br}$ or $-\mathrm{Cl}$ substituent on $\mathrm{C}_{4}$ enhancing the activity for at least sixfold compared to their unsubstituted analogues.

As underlined in Fig. 10, the compounds were submitted to two different binding assays, a GDH-coupled assay and a more sensitive coumarin-based fluorescence assay, which allows the use of the TG2 enzyme at concentrations below $100 \mathrm{nM}$. Interestingly, this fluorometric assay showed that several compounds from this series acted either as partial inhibitors or non-competitive, allosteric inhibitors.

\section{Recently discovered peptidic TG2 inhibitors}

In an extension to their previous studies on the peptidic dihydroisoxazoles (Watts et al. 2006) as TG2 inhibitors, Dafik and Khosla (2011) recently reported new derivatives with interesting TGase inhibitory activity. Developed for labelling and visualizing the catalytically active form of TG2, these compounds incorporate reactive azido or alkynyl functional groups designed for trapping fluorophores or different tags by using alkyne-azide "click" chemistry, as illustrated previously in the literature (Sletten and Bertozzi 2009). The conducted modulations also included the aminoacid moiety in Trp, Tyr or Pro series, the overall SAR trends, observed using kinetic assays on (a): values from the $\mathrm{GDH}$-coupled assay

(b): values from the coumarin-based fluorescence assay

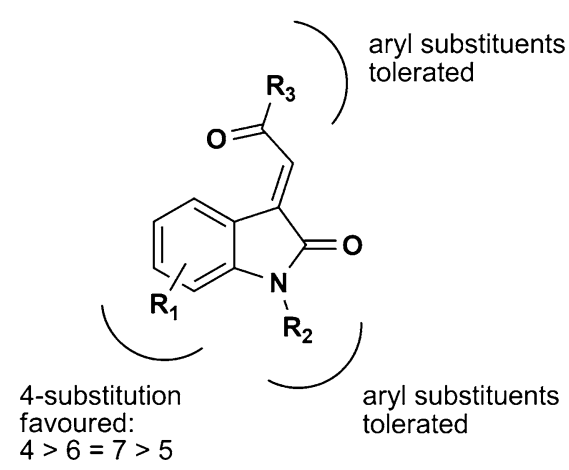

favoured: $4>6=7>5$ tolerated<smiles>O=C1Nc2cccc(Cl)c2/C1=C\C(=O)c1ccc(Cl)cc1</smiles>

$\mathrm{IC}_{50}(\mathrm{a})=0.8 \mu \mathrm{M}$ $\mathrm{IC}_{50}(\mathrm{~b})=0.09 \mu \mathrm{M}$
Fig. 11 SAR trends and one example of inhibitor from the recently reported peptidic dihydroisoxazoles (Dafik and Khosla 2011)<smiles>[R]c1ccc(COC(=O)[Y10]NC[C@H]2CC(Br)=NO2)cc1</smiles> 
AA: Pro $=$ Gly $=$ Phe $>$ Ala $=$ Asp $>$ Lys $>$ Ile

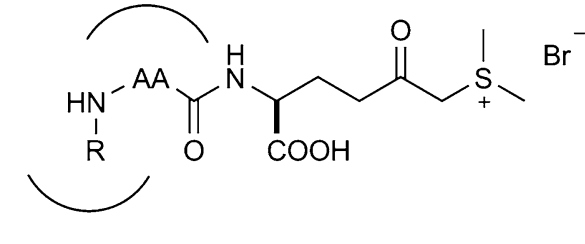

$\mathrm{R}: \mathrm{Cbz}>\mathrm{Fmoc}>t \mathrm{Boc}$

Fig. 12 General structure and SAR of water-soluble TG2 inhibitors (Griffin et al. 2008)

hTG2, are presented bellow (Fig. 11). Some of the synthesized compounds were also tested in a tissue culture wounding model, using the concept validated earlier (Siegel et al. 2008), the most potent inhibitors completely blocking TG2 activity around the "wound" at concentrations as low as $3.1-6.25 \mu \mathrm{M}$.

In their search for aqueous soluble TGase inhibitors that could target preferentially the extracellular pool of TG2, since many of the pathologies that the enzyme is involved in such as fibrosis, celiac disease, multiple sclerosis and cancer are either wholly or partially limited to the extracellular space, Griffin et al. (2008) developed a series of sulfonium peptidylmethylketones related to those published by Pliura et al. (1992). The carboxylic acid and the dimethylsulfonium moieties are key distinguishing features that increase the compound's solubility in water, due to the presence of charges at physiological $\mathrm{pH}$. Beside the variation of the central aminoacid core, the authors also investigated the modification of the carbamate moiety (Fig. 12). Several other warheads based on the imidazolium scaffold could also be tolerated or even enhance the TGase activity (Griffin et al. 2004). Members of this series of compounds have been used successfully in cell studies (Baumgartner et al. 2004; Jones et al. 2006; Telci et al. 2009) and in preclinical studies of diabetic nephropathy and kidney scarring where they induced no animal toxicity up to 120 days and successfully reduce kidney fibrosis and scarring by up to $85 \%$ with a significant increase in kidney function (Johnson et al. 2007, 2008; Huang et al. 2009)

\section{Concluding remarks}

The increasing discovery of tissue transglutaminase involvement in many physiological processes and disease states make it an attractive therapeutic target. Publications in this area are constantly increasing, with the last 4 years being extremely rich in new classes of discovered inhibitors. The usefulness of the screening approaches used for the identification of new active compounds has been confirmed by a number of groups. The reported crystal structures for three of the TG family have further aided inhibitor design and in the case of TG2 revealed the complex conformational dynamics of this multifunctional enzyme. This has led to a more rational drug design phase which no doubt will expand in the immediate future leading to further improvements in the potency and selectivity of possible drug candidates. However, the discovery of a first drug that alleviates one of the disease states that TG2 is involved in by modulation of enzyme function remains a challenging task for the research community.

Acknowledgments E.B. is a research fellow with the support of the Marie Curie Seventh Framework Programme Industry-Academia Partnerships and Pathways (IAPP), TRANSCOM: "The Commercialisation of Transglutaminase" (FP7 No: 251506).

\section{References}

Ahvazi B, Boeshans KM, Idler W, Baxa U, Steinert PM, Rastinejad F (2004) Structural basis for the coordinated regulation of transglutaminase 3 by guanine nucleotides and calcium/magnesium. J Biol Chem 279(8):7180-7192

Baumgartner W, Golenhofen N, Weth A, Hiiragi T, Saint R, Griffin M, Drenckhahn D (2004) Role of transglutaminase 1 in stabilisation of intercellular junctions of the vascular endothelium. Histochem Cell Biol 122(1):17-25

Brunner J (1993) New photolabeling and crosslinking methods. Annu Rev Biochem 62:483-514

Candi E, Paradisi A, Terrinoni A, Pietroni V, Oddi S, Cadot B, Jogini V, Meiyappan M, Clardy J, Finazzi-Agro A, Melino G (2004) Transglutaminase 5 is regulated by guanine-adenine nucleotides. Biochem J 381(Pt 1):313-319

Case A, Stein RL (2007) Kinetic analysis of the interaction of tissue transglutaminase with a nonpeptidic slow-binding inhibitor. Biochemistry 46(4):1106-1115

Castelhano AL, Billedeau R, Pliura DH, Bonaventura BJ, Krantz A (1988) Synthesis, chemistry, and absolute configuration of novel transglutaminase inhibitors containing a 3-halo-4, 5-dihydroisoxazole. Bioorg Chem 16(3):335-340

Chen JS, Mehta K (1999) Tissue transglutaminase: an enzyme with a split personality. Int J Biochem Cell Biol 31(8):817-836

Chica RA, Gagnon P, Keillor JW, Pelletier JN (2004) Tissue transglutaminase acylation: proposed role of conserved active site Tyr and Trp residues revealed by molecular modeling of peptide substrate binding. Protein Sci 13(4):979-991

Choi K, Siegel M, Piper JL, Yuan L, Cho E, Strnad P, Omary B, Rich KM, Khosla C (2005) Chemistry and biology of dihydroisoxazole derivatives: selective inhibitors of human transglutaminase 2. Chem Biol 12(4):469-475

Chung SI, Folk JE (1970) Mechanism of the inactivation of guinea pig liver transglutaminase by tetrathionate. J Biol Chem 245(4): 681-689

Colak G, Keillor JW, Johnson GV (2011) Cytosolic guanine nucledotide binding deficient form of transglutaminase 2 (R580a) potentiates cell death in oxygen glucose deprivation. PLoS One 6(1):e16665

Connellan JM, Folk JE (1969) Mechanism of the inactivation of guinea pig liver transglutaminase by $5,5^{\prime}$-dithiobis-(2-nitrobenzoic acid). J Biol Chem 244(12):3173-3181

Dafik L, Khosla C (2011) Dihydroisoxazole analogs for labeling and visualization of catalytically active transglutaminase 2 . Chem Biol 18(1):58-66 
de Macedo P, Marrano C, Keillor JW (2002) Synthesis of dipeptidebound epoxides and alpha, beta-unsaturated amides as potential irreversible transglutaminase inhibitors. Bioorg Med Chem 10(2):355-360

Duval E, Case A, Stein RL, Cuny GD (2005) Structure-activity relationship study of novel tissue transglutaminase inhibitors. Bioorg Med Chem Lett 15(7):1885-1889

Griffin M, Casadio R, Bergamini CM (2002) Transglutaminases: nature's biological glues. Biochem J 368(Pt 2):377-396

Griffin M, Coutts IG, Saint RE (2004) Novel compounds and methods of using the same. World Patent WO 2004/113363 A2, 29 December 2004

Griffin M, Mongeot A, Collighan R, Saint RE, Jones RA, Coutts IG, Rathbone DL (2008) Synthesis of potent water-soluble tissue transglutaminase inhibitors. Bioorg Med Chem Lett 18(20): $5559-5562$

Halim D, Caron K, Keillor JW (2007) Synthesis and evaluation of peptidic maleimides as transglutaminase inhibitors. Bioorg Med Chem Lett 17(2):305-308

Hitomi K, Kitamura M, Sugimura Y (2009) Preferred substrate sequences for transglutaminase 2: screening using a phagedisplayed peptide library. Amino Acids 36(4):619-624

Huang L, Haylor JL, Hau Z, Jones RA, Vickers ME, Wagner B, Griffin M, Saint RE, Coutts IG, El Nahas AM, Johnson TS (2009) Transglutaminase inhibition ameliorates experimental diabetic nephropathy. Kidney Int 76(4):383-394

Johnson TS, Fisher M, Haylor JL, Hau Z, Skill NJ, Jones R, Saint R, Coutts I, Vickers ME, El Nahas AM, Griffin M (2007) Transglutaminase inhibition reduces fibrosis and preserves function in experimental chronic kidney disease. J Am Soc Nephrol 18(12):3078-3088

Johnson T, Fisher M, Haylor J, Hau Z, Skill N, Jones R, Saint R, Coutts I, El Nahas A, Griffin M (2008) Transglutaminase inhibition ameliorates tissue scarring and fibrosis: experience in a kidney model. J Am Soc 14(8):2052

Jones RA, Kotsakis P, Johnson TS, Chau DY, Ali S, Melino G, Griffin M (2006) Matrix changes induced by transglutaminase 2 lead to inhibition of angiogenesis and tumor growth. Cell Death Differ 13(9):1442-1453

Klock C, Jin X, Choi K, Khosla C, Madrid PB, Spencer A, Raimundo BC, Boardman P, Lanza G, Griffin JH (2011) Acylideneoxoindoles: a new class of reversible inhibitors of human transglutaminase 2. Bioorg Med Chem Lett 21(9):2692-2696

Lai TS, Liu Y, Tucker T, Daniel KR, Sane DC, Toone E, Burke JR, Strittmatter WJ, Greenberg CS (2008) Identification of chemical inhibitors to human tissue transglutaminase by screening existing drug libraries. Chem Biol 15(9):969-978

Leblanc A, Gravel C, Labelle J, Keillor JW (2001) Kinetic studies of guinea pig liver transglutaminase reveal a general-basecatalyzed deacylation mechanism. Biochemistry 40(28): $8335-8342$

Lorand L, Conrad SM (1984) Transglutaminases. Mol Cell Biochem 58(1):9-35

Marrano C, de Macedo P, Gagnon P, Lapierre D, Gravel C, Keillor JW (2001a) Synthesis and evaluation of novel dipeptide-bound 1, 2, 4-thiadiazoles as irreversible inhibitors of guinea pig liver transglutaminase. Bioorg Med Chem 9(12):3231-3241

Marrano C, de Macedo P, Keillor JW (2001b) Evaluation of novel dipeptide-bound alpha, beta-unsaturated amides and epoxides as irreversible inhibitors of guinea pig liver transglutaminase. Bioorg Med Chem 9(7):1923-1928

McGovern SL, Helfand BT, Feng B, Shoichet BK (2003) A specific mechanism of nonspecific inhibition. J Med Chem 46(20): 4265-4272

Okauchi M, Xi G, Keep RF, Hua Y (2009) Tissue-type transglutaminase and the effects of cystamine on intracerebral hemorrhage-induced brain edema and neurological deficits. Brain Res 1249:229-236

Ozaki S, Ebisui E, Hamada K, Goto J, Suzuki AZ, Terauchi A, Mikoshiba K (2010) Potent transglutaminase inhibitors, aryl betaaminoethyl ketones. Bioorg Med Chem Lett 20(3):1141-1144

Ozaki S, Ebisui E, Hamada K, Suzuki AZ, Terauchi A, Mikoshiba K (2011) Potent transglutaminase inhibitors, dithio beta-aminoethyl ketones. Bioorg Med Chem Lett 21(1):377-379

Pardin C, Gillet SM, Keillor JW (2006) Synthesis and evaluation of peptidic irreversible inhibitors of tissue transglutaminase. Bioorg Med Chem 14(24):8379-8385

Pardin C, Pelletier JN, Lubell WD, Keillor JW (2008a) Cinnamoyl inhibitors of tissue transglutaminase. J Org Chem 73(15):5766-5775

Pardin C, Roy I, Lubell WD, Keillor JW (2008b) Reversible and competitive cinnamoyl triazole inhibitors of tissue transglutaminase. Chem Biol Drug Des 72(3):189-196

Pardin C, Roy I, Chica RA, Bonneil E, Thibault P, Lubell WD, Pelletier JN, Keillor JW (2009) Photolabeling of tissue transglutaminase reveals the binding mode of potent cinnamoyl inhibitors. Biochemistry 48(15):3346-3353

Pinkas DM, Strop P, Brunger AT, Khosla C (2007) Transglutaminase 2 undergoes a large conformational change upon activation. PLoS Biol 5(12): 327

Pliura DH, Bonaventura BJ, Pauls HW, Killackey JF, Krantz A (1992) Irreversible inhibition of transglutaminases by sulfonium methylketones: optimization of specificity and potency with omega-aminoacyl spacers. J Enzym Inhib 6(3):181-194

Schaertl S, Prime M, Wityak J, Dominguez C, Munoz-Sanjuan I, Pacifici RE, Courtney S, Scheel A, Macdonald D (2010) A profiling platform for the characterization of transglutaminase 2 (TG2) inhibitors. J Biomol Screen 15(5):478-487

Siegel M, Khosla C (2007) Transglutaminase 2 inhibitors and their therapeutic role in disease states. Pharmacol Ther 115(2):232-245

Siegel M, Strnad P, Watts RE, Choi K, Jabri B, Omary MB, Khosla C (2008) Extracellular transglutaminase 2 is catalytically inactive, but is transiently activated upon tissue injury. PLoS One 3(3): e1861

Sletten EM, Bertozzi CR (2009) Bioorthogonal chemistry: fishing for selectivity in a sea of functionality. Angew Chem Int Ed Engl 48(38):6974-6998

Strnad P, Siegel M, Toivola DM, Choi K, Kosek JC, Khosla C, Omary MB (2006) Pharmacologic transglutaminase inhibition attenuates drug-primed liver hypertrophy but not Mallory body formation. FEBS Lett 580(9):2351-2357

Sugimura Y, Yamashita H, Hitomi K (2011) Screening of substrate peptide sequences for tissue-type transglutaminase (TGase 2) using T7 phage cDNA library. Cytotechnology 63(2):111-118

Telci D, Collighan RJ, Basaga H, Griffin M (2009) Increased TG2 expression can result in induction of transforming growth factor $\beta 1$, causing increased synthesis and deposition of matrix proteins, which can be regulated by nitric oxide. J Biol Chem 284(43):29547-29558

Verhaar R, Jongenelen CA, Gerard M, Baekelandt V, Van Dam AM, Wilhelmus MM, Drukarch B (2011) Blockade of enzyme activity inhibits tissue transglutaminase-mediated transamidation of alpha-synuclein in a cellular model of Parkinson's disease. Neurochem Int 58(7):785-793

Watts RE, Siegel M, Khosla C (2006) Structure-activity relationship analysis of the selective inhibition of transglutaminase 2 by dihydroisoxazoles. J Med Chem 49(25):7493-7501

Wodzinska JM (2005) Transglutaminases as targets for pharmacological inhibition. Mini Rev Med Chem 5(3):279-292

Ziebell MR, Nirthanan S, Husain SS, Miller KW, Cohen JB (2004) Identification of binding sites in the nicotinic acetylcholine receptor for $[3 \mathrm{H}]$ azietomidate, a photoactivatable general anesthetic. J Biol Chem 279(17):17640-17649 